\section{REFERENCES}

Atkinson, R. C., Herrmann, D. J., \& Wescourt, K. T. Search processes in recognition memory. In $R$. L. Solso (Ed.) Theories of cognitive psychology: The Loyola symposium. Washington, D.C.: Winston, 1974. Pp. 101-146.

Baddeley, A. D., \& Ecob, J. R. Reaction time and short-term memory: Implications of repetition effects for the high-speed exhaustive scan hypothesis. Quarterly Journal of Experimental Psychology, 1973, 25, 229-240.

Briggs, E. E., \& Swanson, J. M. Encoding, decoding, and central functions in human information processing. Journal of Experimental Psychology, 1970, 86, 296-308.

Cattell, J. M. Uber die Zeit der Erkennung und Benennung-von Schriftzeichen, Bildern und Farben. Philsophische Studien (L eipzig), 1885, 2, 635-650. Translation in A. T. Poffenberger, James McKeen Cattell, Man of Science. Lancaster, Pennsylvania: The Science Press, 1947. Pp. 13-25.

Cavanagh, J. P. Relation between the immediate memory span and the memory search rate. Psychological Review, 1972, 79, 525-530.
Corballis, M. C., Kirby, J., \& Miller, A. Access to elements of a memorized list. Journal of Experimental Psychology, 1972, 94, 185-190.

Kristofferson, M. W. When item recognition and visual search functions are similar. Perception \& Psychophysics, 1972, 12, 379-384.

Murdock, B. B., Jr. A parallel-processing model for scanning. Perception \& Psychophysics, 1971, 10, 289-291.

Sternberg, S. High Speed scanning in human memory. Science $1966,153,652-654$.

Sternberg, S. Memory scanning: Mental processes revealed by reaction-time experiments. American Scientist, 1969,4 , 421-457.

Theios, J. Smith, P. G., Haviland, S. E., Traupman, J., \& Moy, M. C. Memory scanning is a serial, self-terminating process. Journal of Experimental Psychology, 1972, 97, 323-336.

Wattenbarger, B. L., \& Pachella, R. G. The effect of memory load on reaction time in character classification. Perception \& Psychophysics, 1972, 12, 100-102.

(Received for publication June 14, 1974.)

Bulletin of the Psychonomic Society

1974, Vol. 4 (2A), 75-77

\title{
Age changes in apparent arm length*
}

\author{
J. A. SCHLATER \\ Clark University, Worcester, Massachu setts 01610 \\ A. HARVEY BAKER \\ Educational Testing Service, Princeton, New Jersey 08540 \\ and \\ S. WAPNER \\ Clark University, Worcester, Massachu setts 01610
}

\begin{abstract}
To assess whether an earlier finding-viz., that overestimation of apparent head size was maximal in early childhood and decreased with increase in age (Wapner, 1959)-is generalizable to other body parts, the present study assessed age change in judged length of the outstretched arm with Ss ranging from 7 through 18 years. All age groups underestimated arm length, with the magnitude of underestimation decreasing with increase in age-a pattern opposite to that found for head size. Although the age changes observed for both judged head size and arm length can be described as reflecting an increase in accuracy, such a formulation in terms of accuracy cannot explain why young children maximally overestimate head size and maximally underestimate arm length. It is suggested that future research should explore the possibility that these observed differences reflect differential organization of the body schema at different levels of development.
\end{abstract}

Compared to the body of information amassed concerning body-part size estimation in adults (Fisher, 1970), relatively little research in this area has focused

*This investigation was supported in part by the United Stated Public Health Service Grant MH 00348 from the National Institute of Mental Health. We wish to thank the Leicester, Massachusetts public school system for their cooperation and Irene W. Kostin and Laraine Schwartz for their help at various stages in this research. on children or on age changes. Among the studies using children, several have focused on personality correlates of the body-part size judgments (e.g., Rosenshield, 1962; Shaffer, 1964) rather than on age changes in body-part size judgments per se. One study which examined age changes (Gellert \& Stern, 1964) reported that, with increase in age, judgments of self height increased in precision (i.e., the variability of judgments, as measured 
by average error scores decreased).

Rather than focusing primarily upon age changes in precision of judgment, the present paper deals with age change in the direction of errors in body-part size judgments (over- or underestimation, assessed by constant error scores). Pertinent to this issue are some findings (Wapner, 1959) on size judgments of width of the head (temple to temple). While all ages (4 to 49) overestimated head size, confirming earlier adult data (Werner, Wapner, \& Comalli, 1957), this overestimation was maximal at the youngest age (4 to 5), decreased sharply to age nine and then leveled off.

To determine whether the pattern of age change for judged head size (from large to small overestimation) also holds for other body parts, the present study assessed age changes in judged length of the outstretched arm.

\section{METHOD}

The sample consisted of $72 \mathrm{Ss}$, comprised of six age groups of 12 Ss each, with 6 males and 6 females in each group. Mean ages in months for the six groups, respectively, were: 85.7, 107.6, $132.4,158.8,189.4,215.0$. IQs were obtained from school records based on the California Test of Mental Abilities; for the occasional $\mathrm{S}$, when a score on this test was not available, IQ was based on the Otis. Mean IQ scores for the six groups, respectively, were: $108,106,104,103,107$, and 102 .

The task for $\mathrm{S}$, while sitting in a darkened room, was to extend the preferred arm straight out in front of him with four fingers extending straight forward with palm parallel to the floor, and to tell $\mathrm{E}$ how to adjust a luminous indicator toward or away from him to a position experienced by $S$ to be directly over his fingertips. ${ }^{1}$

Some earlier findings with adults (McFarland, Wapner, \& Werner, 1960) suggested that judged length of the outstretched arm may be greater when raised to point at a target as compared to when simply raised without pointing. Because there might be age changes in the effect of pointing, this variable was included in the present study. Within each age and sex group, therefore, the instrumental relationship between the arm and a target was varied, as follows: half the Ss were simply told to raise and extend the arm and hand forward while the room was dimly lit and a target thus visible. Each remaining $S$ was instructed to raise and extend the arm in order to "point" to the target (bull's eye) which was located $30 \mathrm{~cm}$ from the fingertips of his outstretched arm. The position of the arm and hand was identical for both types of instruction. The room was then darkened so that neither the fingertips nor the target were visible during the trials them selves.

One ascending (initial position of the indicator $20 \mathrm{~cm}$ toward $S$ from fingertip location) and one descending (indicator initially $20 \mathrm{~cm}$ beyond fingertip location) trial was used in counterbalanced order, with a total of two trials for each S. The score used in the analysis was the mean for the two trials of the deviation of apparent from objective fingertip location. A minus score arbitrarily represented underestimation or deviation closer to $\mathrm{S}$ than his fingertips and a positive score represented overestimation or deviation further away from $\mathrm{S}$ than his fingertips.

Since S's fingertip location might vary slightly during the course of a trial, measurements of objective fingertip location were taken at the beginning and at the end of each trial. The mean of the pre- and posttrial measures was taken as the best value available of objective arm length. In addition, these data on extent of actual fingertip movement during a trial were analyzed to ascertain whether any obtained age changes in judged arm length were related to age differences in extent of fingertip motion.

\section{RESULTS}

Although our main interest was in assessing age change in judged arm length, overall differences (underestimation or overestimation) between judged and objective arm length were also assessed. If no overall effect of over- or underestimation occurred, the mean distribution of observed differences would not deviate systematically from zero. A t test indicated that it was appropriate to reject the hypothesis that the population mean was zero $(\mathrm{t}=5.49$, $\mathrm{df}=71, \mathrm{p}<.001)$. The observed mean, $-2.43 \mathrm{~cm}$, indicated that judged arm length was less than objective arm length. This underestimation effect held for each age group and for 54 out of the 72 Ss.

The variable of central interest, age change, was assessed as part of a 6 (age) by 2 (sex) by 2 (pointing) between-groups factorial analysis of variance. Only the main effect for age was significant $(F=3.31$, $\mathrm{df}=5,48$, $\mathrm{p}<.02$ ). Mean values from the youngest to the oldest age groups were, respectively, as follows: $-4.9,-0.9$, $-4.4,-0.4,-2.7$, and $-1.3 \mathrm{~cm}$. Results from a linear trend analysis $(\mathrm{F}=3.61, \mathrm{df}=1,66, \mathrm{p}<.10)$ indicate that the age function has positive slope-i.e., the magnitude of underestimation decreased with increase in age. In addition, a 2 by 2 chi square was undertaken. On one axis of classification, the scores were categorized as above or below the median of the total sample and on the other axis, Ss were categorized as being younger (first three age groups) vs older (last three age groups). A significant effect was found $\left(\chi^{2}=5.6, \mathrm{df}=1, \mathrm{p}<.02\right)$. Only $36 \%$ of the younger Ss scored above the median whereas $64 \%$ of the older Ss scored above the median-i.e., younger Ss more frequently showed greater underestimation.

The above findings, taken as a set indicate that, relative to objective arm length, there is underestimation of judged arm length which decreases with increase in age. Stated in other terms, relative to objective arm length, apparent arm length increases with increase in age.

To assess whether the above age finding might reflect age differences in maintaining the hand and arm in the initial location during the trials, the mean amount of movement, away from the body (coded "+") or toward the body (coded "-") was computed for each S. The results from an analysis of variance on these data showed an effect approaching the conventional level of significance $(F=2.05, \mathrm{df}=5 / 48, \mathrm{p}<.10)$. The mean values from the youngest to oldest age groups respectively were: $-0.75,-0.66,-0.94,-1.73,-0.25$, and $-0.44 \mathrm{~cm} .{ }^{2}$ As can be seen, there is no pattern of systematic increase or decrease here ( $F$ for linear trend $<1, \mathrm{df}=1 / 48, \mathrm{p}=\mathrm{n} . \mathrm{s}$.). There is thus no evidence that the observed age change in judged arm length 
simply reflects age differences in amount of arm-hand movement during the trials.

\section{DISCUSSION}

The main findings of the present experiment were that judged arm length was underestimated with all age groups pooled and that the underestimation decreased with increase in age. This pattern for judged arm length is opposite to that found for judged head size earlier, viz, that head size was overestimated across age groups and that the amount of overestimation decreased with increase in age (Wapner, 1959).

How might these two opposite sets of findings for judged head size and apparent arm length be explained? Since body-part size estimates are highly susceptible to differences in method (cf. Fisher, 1970), this issue will be examined first. Regarding head size, the general adult pattern of overestimation appears to hold across several different methods (Nash, 1951; Shontz, 1969; Werner, Wapner, \& Comalli, 1957).

The finding that overestimation of judged head size decreased with increase in age (Wapner, 1959) came from a study which had an unusual methodological feature-only ascending trials were used. For this reason, the question arises: Might this finding of age change be an artifact of an interaction between age and psychophysical method such as Wohlwill (1960) discussed? Our own prior research regarding age changes in ascending relative to descending trials indicates that the observed findings for head size are quite different from those that might be expected if method bias were playing a role. First, the use of ascending trials only should lead to a general effect of underestimation for all age groups; instead, overestimation was observed here. Second, since children have been found to show greater anticipation error than adults, the smallest estimates should have been observed at the youngest age levels (Baker, 1972; Wapner, 1968; Wapner \& Werner, 1957), whereas the largest estimates were observed at the youngest age levels. In sum, since the observed pattern of age change in head size is the exact opposite of that which would be expected from the use of only ascending trials, method bias cannot account for this observed age change.

The method used here for assessing judged arm length employed both ascending and descending trials. Previous studies with diverse tasks (e.g., Baker, 1972; Wapner, 1968; Wapner \& Werner, 1957) using point of subjective equality scores derived from the methods of limits and adjustment have shown neither a general tendency to induce underestimation or overestimation, nor evidence of age differences in such constant errors. There is no reason, therefore, to suspect that the psychophysical procedure artifactually produced either the overall effect or the age differences. Another aspect of our procedure involved assessment of arm length while the arm and hand were extended forward. Using a much different procedure, Gellert and Stern (1964), in the only study known to us which assessed the development of arm length judgments, indicate that each age and sex group assessed underestimated arm length. (They provide no basis of knowing whether or not age differences in such judgments obtained.) The overall underestimation thus apparently holds across diverse methods.

Another possible formulation of the age-change findings might involve the notion of accuracy. The decrease in underestimation found for judged arm length and the decrease in overestimation for judged head size both can be described in terms of change toward more accurate estimates of objective size as age of the Ss increases. While an interpretation in terms of accuracy seems plausible with regard to the direction of age change, it is powerless to explain why young children maximally underestimate arm length and maximally overestimate head size.
An accuracy interpretation is therefore insufficient to account for some major features of these data.

While no explanation of the findings regarding age changes in judged head size and judged arm length are offered here, two concluding points may be made. First, a substantive interpretation of these findings may be warranted since (a) judged size of body parts are not reflective of their actual size, and (b) these differences from objective size do not seem interpretable in terms of accuracy or methodological artifact. Secondly, it is our hunch that the difference in direction of age change observed for judged head size as compared with judged arm length reflects real differences in the organization of the body schema or body image at various levels of development, and not simply age differences in ability to make accurate judgments. Clearly, further research is needed to explore this and other possible formulations regarding age changes in underestimation/overestimation of judged size of body parts.

\section{REFERENCES}

Baker, A. H. Psychophysical error of anticipation and the method of limits: A developmental analysis. In L. F. Mönks and W. W. Hartup (Eds.), Determinants of behavioral development. New York: Academic Press, 1972.

Fisher, S. Body experience in fantasy and behavior. New York: Appleton-Century-Crofts, 1970.

Gellert, E., \& Stern, J. B. Age and sex differences in children's judgments of their height and body proportions. Presented at the Annual Meeting of the American Psychological Association, Los Angeles, 1964.

Humphries, O. Effect of articulation of finger-tip through touch on apparent length of outstretched arm. Unpublished master's thesis, Clark University, 1959.

McFarland, J. H., Wapner, S., \& Werner, H. Factors affecting body image as measured by perceived arm length. Presented at the Annual Meeting of the Eastern Psychological Association. New York, 1960.

Nash, $\mathrm{H}$. The estimation of body size in relation to actual body size, personal ethos and developmental status. Unpublished doctoral dissertation, University of California, 1951.

Rosenshield, P. B. Relationships among perceived height parental control, and direction of aggression. Unpublished masters thesis, University of Kansas, 1962.

Schlater, J. A. Body perception as a function of self:world orientation. Unpublished master's thesis, Clark University, 1969.

Shaffer, J. P. Social and personality correlates of children's estimates of height. Genetic Psychology Monographs, 1964, 70, 97-134.

Shontz, F. Perceptual and cognitive aspects of body experience. New York: Academic Press, 1969.

Wapner, S. Some experiments on body image from the viewpoint of organismic and developmental theory. Presented at the Annual Meeting of the American Psychological Association, Cincinnati, 1959

Wapner, S. Age changes in perception of verticality and of the longitudinal body axis under body tilt. Journal of Experimental Child Psychology, 1968, 6, 543-555.

Wapner, S., \& Werner, H. Perceptual development. Worcester. Massachusetts: Clark University Press, 1957.

Werner, H., Wapner, S., \& Comalli, P. E., Jr. Effect of boundary on perception of head size. Perceptual \& Motor Skills, 1957, 7, 69-71.

Wohlwill, J. F. Developmental studies of perception. Psychological Bulletin, 1960, 57, 249-288.

\section{NOTES}

1. This way of operationally measuring "judged arm length" has been used by prior investigators (e.g., Humphries, 1959; Schlater, 1969) and has been found to give results congruent with other procedures in which the $S$ made qualitative judgments regarding "how long his arm felt."

2 . The mean across age groups is $-0.80 \mathrm{~cm}$. Thus, the maximal "bias" possible in taking the mean of the pre- and posttrial values of fingertip location-if one wishes to reject our assumption that this is the best available estimate-is $-0.40 \mathrm{~cm}$, a value which is only $16 \%$ of the overall underestimation effect observed $(-2.43 \mathrm{~cm})$.

(Received for publication April 16, 1974.) 